\title{
Global surveillance system to monitor the development of drug resistance in Mycobacterium leprae
}

This article was published in the following Dove Press journal:

Research and Reports in Tropical Medicine

30 November 2015

Number of times this article has been viewed

\author{
Masanori Matsuoka \\ Leprosy Research Center, National \\ Institute of Infectious Diseases, \\ Higashimurayama, Tokyo, Japan
}

\begin{abstract}
Leprosy is a chronic disease caused by Mycobacterium leprae infection. Multidrug therapy, which consists of dapsone, rifampicin, clofazimine, and quinolone, is the currently accepted strategy for leprosy control. However, drug-resistant cases of M. leprae have been reported sporadically in some countries or areas soon after the initiation of dapsone chemotherapy. Susceptibility or resistance to antileprosy drugs has been determined using the mouse footpad method since the 1960s. Obtaining comprehensive data on the prevalence or dissemination of resistant strains has been hampered due to the methodological faults of the method. However, recent findings on relationships between resistance to dapsone, rifampicin, and quinolones and genetic background have enabled the detection of resistance to these key drugs by analyzing amino acid substitution in a drug resistance determining region. Resistance to drugs used in multidrug therapy is a concern of the WHO Global Leprosy Programme. Global surveillance of drug resistance was instituted in 2008 to assess the level of drug resistance and evaluate the efficacy of the current leprosy control strategy. The surveillance network consists of sentinel sites in 18 countries for sample collection and 18 reference centers for mutation detection by PCR direct sequencing. To date, results indicate that drug-resistant $M$. leprae does not threaten the current globally accepted procedures for the control of leprosy.
\end{abstract}

Keywords: leprosy, drug resistance, global surveillance

\section{Introduction}

Leprosy is a chronic disease caused by infection with the bacterium Mycobacterium leprae. It is an old disease, with the evidence of its characteristic pathological alterations in a 4,000-year-old human skeleton in Rajasthan, India. ${ }^{1}$ During the last decade, approximately 150,000 new cases were detected annually worldwide (Figure 1). ${ }^{2}$ The data show that the annual trend in new cases, which is largely governed by the leprosy situation in India, is not changed much in other countries. Although rapid control of transmission was expected following the treatment of multibacillary (MB) cases with bactericidal drugs, the decline in new cases is very gradual. Sequelae such as deformities, peripheral neuropathy, and disabilities, result if patients are not treated during the early stages of the disease. Therefore, timely diagnosis and adequate chemotherapy are essential for effective treatment. Although multidrug therapy (MDT) consisting of dapsone, rifampicin, clofazimine, and ofloxacine (Table 1) is the current strategy for leprosy control programs, ${ }^{3}$ many drug-resistant cases have been reported sporadically in many areas of the world..$^{4-9}$ Drug resistance in many infectious diseases, for example tuberculosis, threatens disease control. Comprehensive data on the extent of drug resistance in leprosy have not been available. Drug resistance in M. leprae,
Correspondence: Masanori Matsuoka Leprosy Research Center, National Institute of Infectious Diseases,

4-2-I Aoba-cho, Higashimurayama,

Tokyo 189-0002, Japan

$\mathrm{Tel}+8 \mathrm{I} 423 \mathrm{9l} 82 \mathrm{II}$

Fax $+8 \mid 423949092$

Email matsuoka@nih.go.jp 


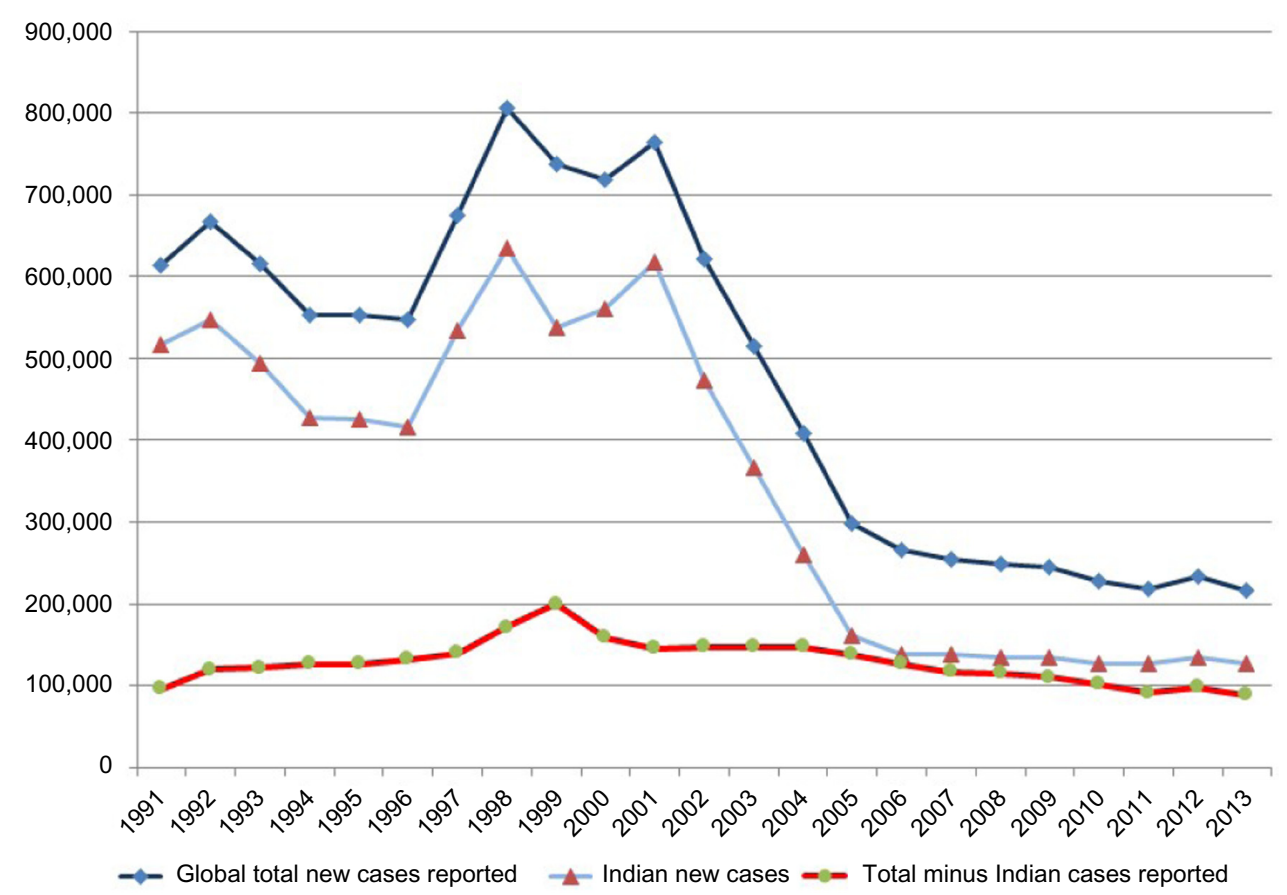

Figure I Global trend of new case detection.

especially for rifampicin, was a serious concern for the WHO Global Leprosy Programme (GLP). Therefore, GLP began a sentinel surveillance program to monitor $M$. leprae drug resistance and evaluated the efficacy of MDT. This review describes the sentinel surveillance project, the antibiotics used for leprosy treatment, the molecular basis of drug resistance to these antibiotics, and the methodology used to detect resistant strains.

\section{Antileprosy drugs and drug resistance}

Chaulmoogra oil is an ancient leprosy treatment, but its efficacy was uncertain and relapse was common. ${ }^{10,11}$ Modern

Table I WHO/MDT regimen for adults

\begin{tabular}{llll}
\hline & Criteria & Dose & Duration \\
\hline MB & $\geq 6$ skin lesions, & Rifampicin: $600 \mathrm{mg}$ once a month & 12 months \\
& $\begin{array}{l}\text { or positive } \\
\text { bacterial index }\end{array}$ & $\begin{array}{l}\text { Dapsone: } 100 \mathrm{mg} \text { daily } \\
\text { Clofazimine: } 300 \mathrm{mg} \text { once a }\end{array}$ & \\
& & month and $50 \mathrm{mg}$ daily & \\
PB & $\leq 5$ skin lesions & Rifampicin: $600 \mathrm{mg}$ once a month & 6 months \\
& $\begin{array}{l}\text { and negative } \\
\text { bacterial index }\end{array}$ & Dapsone: $100 \mathrm{mg}$ daily & \\
\hline
\end{tabular}

Notes: Rifampicin and clofazimine are given monthly and supervised. Single lesion paucibacillary type (SLPB) is treated with a single dose of rifampicin $(300 \mathrm{mg})$, ofloxacin (200 mg), and minocycline $(50 \mathrm{mg})$. The report of the 8th WHO expert committee on leprosy excluded SLPB. Reprinted from WHO Expert Committee on Leprosy: 8th Report. Geneva:World Health Organization. Available from: http://www.searo.who. int/entity/global_leprosy_programme/publications/8th_expert_comm_2012.pdf. Accessed August 3, 2015. Copyright 2012. ${ }^{3}$ Ofloxacin and minocycline are used for patients who refuse to take clofazimine.

Abbreviations: MDT, multi-drug therapy; MB, multibacillary; PB, paucibacillary. chemotherapy began with the introduction of heat-stable, water-soluble promin (diaminoazobenzene- $4^{\prime}$-sulfonamide) in $1941 .{ }^{12}$ Injectable promin was replaced by a more effective oral sulfone, dapsone (4-4'-diaminodiphenyl sulfone, DDS), 6 years later ${ }^{13,14}$ Rifampicin, clofazimine, and minocycline were introduced subsequently.

\section{Dapsone}

Dapsone is still a fundamental antileprosy compound even in the MDT era. It is a bacteriostatic compound that targets the folic acid biosynthesis pathway. Dapsone is an analog of $p$-aminobenzoic acid and acts as a competitive inhibitor of $p$-aminobenzoic acid. Dapsone binds to dihydropteroate synthase (DHPS), which is encoded by the folPl gene, and inhibits folic acid synthesis. Due to its bacteriostatic property, dapsone was administered as a lifelong monotherapy until the advent of MDT in the 1980s. Side effects are uncommon, and the drug is well-tolerated; however, a rare allergic reaction to dapsone, known as dapsone hypersensitivity syndrome, can occur (Figure 2). ${ }^{15}$ Resistance to dapsone: the first suspected cases of sulfone resistance were reported in $1953,{ }^{16}$ but a methodology to confirm resistance was not available until the mouse footpad assay was developed in $1960 .{ }^{17}$ Using this assay, three of seven clinically suspected cases of dapsone resistance were confirmed based on growth in the footpad of a mouse given a diet containing $0.1 \%$ dapsone. ${ }^{4}$ The number of dapsone-resistant cases 


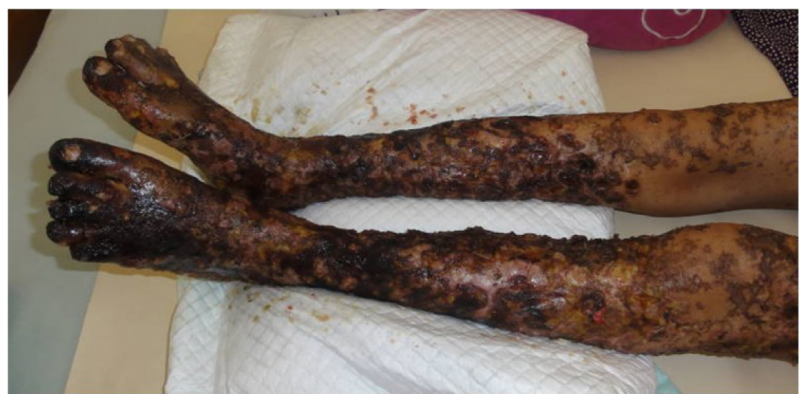

Figure 2 A case of dapsone hypersensitivity syndrome (DHS). Patient-caused skin ulcers with fever and vasculitis. Symptoms are identical to those of Lucio's phenomenon and differential diagnosis was difficult. Photo courtesy of Professor Indropo Agusni, Institute of Tropical Disease, Airlangga University, Surabaya, Indonesia.

including primary resistant strains, resistant bacilli from a patient without previous administration of any antileprosy drugs, and secondary dapsone resistance increased following long periods of monotherapy., ${ }^{4,518,19}$ Therefore, the bacteriostatic effect and lifelong treatment facilitated dapsone resistance in leprosy patients.

A relationship between amino acid substitutions in DHPS and dapsone resistance has been revealed. ${ }^{20,21}$ Dapsone cannot bind DHPS if certain missense mutations are present in the folP1 gene, resulting in dapsone-resistant bacilli. Missense mutations at codon 53 (ACC) or 55 (CCC), encoding threonine or proline, in folP 1 confer dapsone resistance (Figure 3). Mutations detected in the folP1 gene in dapsone-resistant
Table 2 Mutations detected in drug-resistant isolates confirmed by mouse footpad testing

\begin{tabular}{|c|c|}
\hline & Reference \\
\hline \multicolumn{2}{|l|}{ folPI gene: codon and mutation } \\
\hline 53: Tre(ACC) $\rightarrow \| l e($ ATC $)$ & $20,22,24,25$ \\
\hline 53: $\operatorname{Tre}(\mathrm{ACC}) \rightarrow \operatorname{Val}(\mathrm{GTC})$ & 22,23 \\
\hline 53: Tre(ACC) $\rightarrow$ Ala(GCC) & 22,25 \\
\hline 53: $\operatorname{Tre}(\mathrm{ACC}) \rightarrow \operatorname{Ser}(\mathrm{TCC})$ & 21,25 \\
\hline 53: $\operatorname{Tre}(\mathrm{ACC}) \rightarrow \operatorname{Arg}(\mathrm{AGG})$ & 25 \\
\hline 53: $\operatorname{Tre}(\mathrm{ACC}) \rightarrow \operatorname{Arg}(\mathrm{AGA})$ & 23 \\
\hline 55: Pro $(C C C) \rightarrow \operatorname{Ser}(T C C)$ & 24 \\
\hline 55: Pro(CCC) $\rightarrow$ Leu(CTC) & $20-25$ \\
\hline 55: Pro $(C C C) \rightarrow \operatorname{Arg}(C G C)$ & 22,25 \\
\hline 55: Pro(CCC) $\rightarrow$ Ala(GCC) & 21 \\
\hline 55: Pro(CCC) $\rightarrow \operatorname{Arg}(C G T)$ & 22 \\
\hline \multicolumn{2}{|l|}{ rpo $B^{*}$ gene: codon and mutation } \\
\hline 438: $\mathrm{Gln}(\mathrm{CAG}) \rightarrow \operatorname{Val}(\mathrm{GTG})$ & 30 \\
\hline 44I: Asp(GAT) $\rightarrow$ Tyr(TAT) & 24,33 \\
\hline 45I: His(CAC) $\rightarrow \operatorname{Try}(T A C)$ & 24 \\
\hline 456: $\operatorname{Ser}($ TCG $) \rightarrow$ Leu(TTG) & $24,28-32$ \\
\hline 456: $\operatorname{Ser}(\mathrm{TCG}) \rightarrow \operatorname{Met}(\mathrm{ATG})$ & 28 \\
\hline 456: $\operatorname{Ser}(\mathrm{TCG}) \rightarrow$ Phe (TTC) & 28 \\
\hline 440: Met(ATG) $\rightarrow$ insertion & 28 \\
\hline \multicolumn{2}{|l|}{ Lys, Phe (AGTTCA) } \\
\hline \multicolumn{2}{|l|}{ gyrA gene: codon and mutation } \\
\hline 9I: $\mathrm{Ala}(\mathrm{GCA}) \rightarrow \mathrm{Val}(\mathrm{GTA})$ & $24,31,32,41$ \\
\hline \multicolumn{2}{|c|}{$\begin{array}{l}\text { Notes: *Codons are numbered using the } M \text {. leprae numbering system. Codon } 438 \\
\text { of the rpoB gene corresponds to } 513 \text { in reference } 30 \text {, codon } 441 \text { corresponds to } \\
516 \text { in reference } 24 \text {, and } 410 \text { in reference } 33 \text {, codon } 451 \text { corresponds to } 420 \text { in } \\
\text { reference } 24 \text {, codon } 456 \text { corresponds to } 425 \text { in references } 24,31 \text {, and } 32 \text {, codon } \\
456 \text { also corresponds to } 531 \text { in references } 28,29 \text {, and } 30 \text { respectively. Codon } 440 \\
\text { in the rpoB gene corresponds to codon } 409 \text { in reference } 28 \text {. Mutations reported } \\
\text { without confirmation of resistance by the mouse footpad assay are not included. }\end{array}$} \\
\hline
\end{tabular}

Dapsone: folP1 threonine (ACC) at 53, proline (CCC) at 55

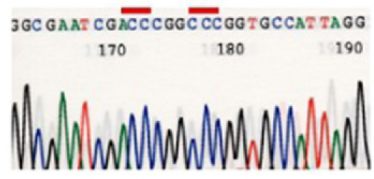

Rifampicin: $\quad$ rpOB Glutamine (CAG) at 438, aspartic acid (GAT) at 441, Histidine (CAC) at 451, serine (TCG) at 456, leucine (CTG) at 458

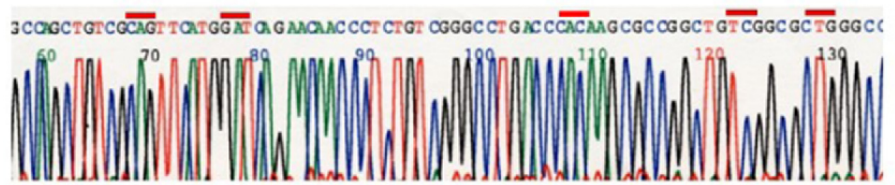

Quinolone: gyrA Glycine (GGC) at 89, alanine (GCA) at 91, serine (TCG) at 92, aspartic acid (GAC) at 95

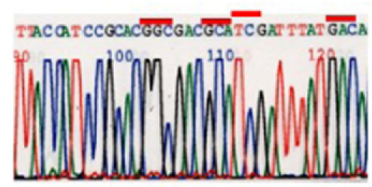

Figure 3 Mutations confirmed to confer drug resistance.

Notes: Mutation at codon 428 in the rpoB gene has not been detected in a drug-resistant isolate, but it is assumed the amino acid substitution would confer rifampicin resistance based on findings in Mycobacterium tuberculosis. Likewise, mutations at codons 89,92 , and 95 in the gyrA gene are predicted to cause quinolone resistance. 
M. leprae and confirmed by mouse footpad testing are shown in Table $2 .^{20-25}$

\section{Rifampicin}

Semi-synthetic rifampicin, 3-[[(4-methyl-1-piperazinyl) imino]methyl], is a highly bactericidal compound. As recommended by WHO, rifampicin is currently a key component in MDT for leprosy (Table 1). The drug is included in all MDT regimens, with a usual adult dose of $600 \mathrm{mg} / \mathrm{month}$, by mouth. ${ }^{3}$ Rifampicin targets the beta $(\beta)$ subunit of RNA polymerase, which is encoded by the $r p o B$ gene, and inhibits DNA-dependent mRNA transcription.

\section{Resistance to rifampicin}

Rifampicin was initially administered as a monotherapy or in combination with dapsone. The first rifampicin-resistant case was reported in 1976 in an isolate from a relapsed patient on rifampicin monotherapy, who was previously treated with dapsone. ${ }^{6}$ Out of 45 relapsed cases previously treated with rifampicin alone or in combination with dapsone, nine were resistant to rifampicin and seven of those nine were also resistant to dapsone. ${ }^{7}$ Another study showed 19 of 35 relapsed cases were resistant to both dapsone and rifampicin, with three isolates resistant to rifampicin alone. ${ }^{5}$ The increase in rifampicin resistance led to the introduction of MDT in the 1980s to prevent further spread of drug-resistant cases.

Susceptible strains shift to rifampicin resistance with the introduction of missense mutations at codons 438, 441, 451, 456, and 458 (Figure 3 ). The binding of rifampicin to RNA polymerase is blocked by these amino acid substitutions in the $\beta$ subunit. Missense mutation TCC (Ser) to TCG (Leu) at codon 456 is more frequently observed in rifampicin-resistant isolates of M. leprae and Mycobacterium tuberculosis. ${ }^{9,26,27}$ An exceptional rifampicin-resistant isolate with a 6-bp insertion in codon 440 has been reported. ${ }^{28}$ Mutations detected in rifampicin-resistant isolates are shown in Table $2 .^{24,28-33}$

\section{Clofazimine}

Clofazimine (B663, Lamprene) [3-( $p$-chloroanilino)-10-( $p$ chlorophenyl)-2,10-dihydro-2-(isopropylimino)phenazine], is a weakly bactericidal against $M$. leprae. The mechanism of action has not been fully elucidated; however, a possible bactericidal mechanism of clofazimine is via binding to GC-rich domains of bacterial DNA. ${ }^{34}$ Clofazimine has a weak antiinflammatory effect and it helps to control the type 2 reaction (erythema nodosum leprosum). Discoloration of the skin, with increased pigmentation is a side effect of clofazimine.
Although skin pigmentation gradually disappears within 1-2 years after therapy is terminated, ${ }^{35}$ some patients refuse clofazimine treatment due to this side effect.

\section{Resistance to clofazimine}

Clofazimine has been used for leprosy treatment for over four decades. However, resistance to the drug is rare. Only one reported case has shown clear clofazimine resistance by the mouse footpad testing. ${ }^{36}$ Other preliminary reports of drug-resistant cases are equivocal since bacillary growth was not clear or the amount of clofazimine administrated was not adequate. Some strains do not grow in the footpad of a mousegiven feed supplemented with $0.0001 \%$ clofazimine, but other strains grow with very low concentration of clofazimine. ${ }^{37,38}$ Another study showed no cases of resistance to clofazimineresistant cases in 21 isolates tested using the mouse footpad assay with $0.001 \%$ clofazimine in diet. ${ }^{24}$ It appears that a concentration of $0.0001 \%$ is the critical concentration for clofazimine in the mouse footpad susceptibility assay. Although drug resistance to clofazimine is not detectable using a molecular method, it might nevertheless be negligible.

\section{Ofloxacin}

Ofloxacin (4-fluoroquinolone) is a moderately bactericidal antibiotic against $M$. leprae. Ofloxacin binds the A subunit of DNA gyrase and inhibits DNA replication. Ofloxacin was previously administered with rifampicin and minocycline for single legion paucibacillary cases, but the last meeting of experts excluded single legion paucibacillary. It is now treated with the same regimen as paucibacillary $(\mathrm{PB})$ cases (Table 1). ${ }^{3}$ Ofloxacin is also administered to patients who cannot take clofazimine or rifampicin, in combination with minocycline. ${ }^{3}$

\section{Resistance to ofloxacin}

Amino acid substitutions in the gyrA subunit of gyrase, encoded by the gyrA gene, and quinolone resistance have been found in most of the ofloxacin-resistant strains of mycobacteria (Figure 3). ${ }^{39,40}$ The first reported case of $M$. leprae resistant to ofloxacin was also resistant to dapsone and rifampicin, based on the mouse footpad assay and mutation detection at codon 91 of the gyr $A$ gene. ${ }^{31}$ Two other instances of ofloxacin-resistant $M$. leprae in Japan were relapsed cases reported in 2000 and 2003. ${ }^{32,41}$ Altogether, possible ofloxacinresistant cases, of which resistance has not been confirmed by the mouse footpad method, were found in $\mathrm{Japan}^{8}$, Korea, ${ }^{42}$ Mexico, ${ }^{43}$ and Brazil ${ }^{44}$ with mutation at codon 91 in eight cases and in one case at codon 89. 
Two other amino acid changes, at codon 91 (Ser) and codon 94 (Asp) (M. tuberculosis codon numbering system), in gyrA of M. tuberculosis have been associated with quinolone resistance. ${ }^{45}$ Consequently, it is predicted that mutations at codons 89,92 , and 95 (M. leprae codon numbering system) in gyrA of M. leprae will also confer quinolone resistance. An in vitro molecular model also forecasts that a mutation at this position would cause quinolone resistance. ${ }^{46}$ A mutation at codon 89 in the gyr $A$ gene has been detected, but resistance to ofloxacin was not assessed with the mouse footpad assay. ${ }^{8}$ Although a mutation has not been found at codon 95 , in vitro assays strongly suggest that mutation(s) at codon 95 confers quinolone resistance to $M$. leprae ${ }^{47}$ The prevalence of ofloxacin resistance is still low, even in some areas with high leprosy prevalence. ${ }^{23}$

Minocycline is used as a second line antileprosy drug in accordance with the current MDT strategy from WHO. ${ }^{3}$ Tetracycline inhibits protein synthesis by binding to the $30 \mathrm{~S}$ ribosomal subunit, blocking the binding of aminoacyl transfer RNAs to the messenger RNA ribosomal complex. ${ }^{48}$

Minocycline resistance has not been reported in M. leprae. The susceptibility of 21 clinical isolates to minocycline was examined using the mouse footpad assay. ${ }^{24}$ No cases of minocycline resistance were found among them. Other antibiotics such as clarithromycin are also effective against leprosy. ${ }^{49}$ No reports of clarithromycin resistance have been made.

\section{Standard multidrug therapy recommended by WHO}

Dapsone monotherapy continued for many years and led to many dapsone-resistant cases until rifampicin was introduced for leprosy treatment. ${ }^{18,19}$ Rifampicin, as a monotherapy or combined with dapsone for the treatment of dapsone-resistant leprosy led to the rapid selection of rifampicin-resistant bacilli. ${ }^{5-8}$ WHO initiated a global MDT program in 1982 to halt the further emergence and spread of drug resistance, improve treatment efficacy, and to interrupt transmission of infection in the community. ${ }^{50}$

Leprosy has a wide range of clinical features based on host immunity against $M$. leprae infection: I (indeterminate leprosy) TT (tuberculoid); BT (borderline tuberculoid); BB (mid-borderline); BL (borderline lepromatous); and LL (lepromatous).$^{51}$ However, for treatment purposes and to make diagnosis easier for health workers under field conditions, a simple classification scheme was introduced. Different disease groups were divided into two types, $\mathrm{PB}$ and MB. PB is defined as any new case with up to five skin lesions, while MB leprosy is any new case with more than five skin lesions. The MDT regimen consists of rifampicin, dapsone, and clofazimine (Table 1). ${ }^{3} \mathrm{MB}$ patients are treated for 12 months, and PB patients are treated for 6 months.

\section{Methodology for detecting drug-resistant leprosy in global surveillance}

A method to examine and confirm M. leprae drug resistance was not established until mouse footpad assay was developed in $1960 .{ }^{17}$ The method was first applied to susceptibility testing of M. leprae in $1964 .{ }^{4}$ The method is tedious and not applicable for many samples. Elucidation of the genomic basis of drug resistance to dapsone, rifampicin, and ofloxacin enables the examination of resistance to these drugs by detecting mutation in a drug resistance determining region (DRDR). Direct sequencing is the method for detecting mutations that confer drug resistance. Although clofazimine and minocycline are prescribed for some patients, a molecular test for detecting resistance to these two drugs is not available. However, resistance to clofazimine is practically nil and no case of minocycline resistance has been reported. Therefore, most drug-resistant cases to drugs used in MDT are detectable by mutation detection in DRDRs using PCR direct sequencing.

Resistance to dapsone is classified into three levels (high, intermediate, and low) according to bacillary growth in the mouse footpad assay with the diet supplemented with different concentrations of dapsone (0.01, 0.001, and $0.0001 \%$ ). Some strains of $M$. leprae obtained from untreated leprosy patients were consistently inhibited by $0.0001 \%$ dapsone

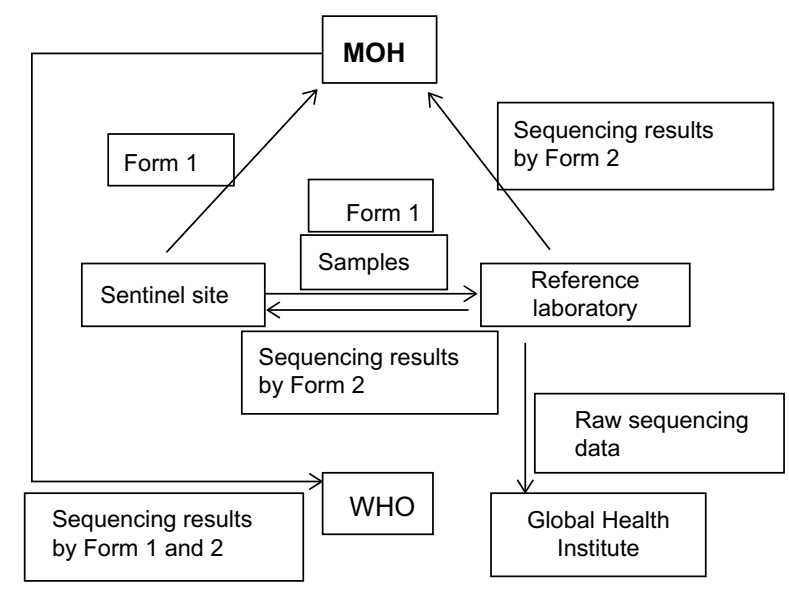

Figure 4 Structure of drug resistance surveillance in leprosy.

Notes: Form I includes patient details. Sequence analysis results are reported on form 2. Both forms are included in the Guidelines for Global Surveillance of Drug Resistance in Leprosy. ${ }^{55}$ Raw sequence data are compiled at the Global Health Institute to analyze mutation frequencies.

Abbreviation: $\mathrm{MOH}$, Ministry of Health. 
Table 3 Sentinel sites and reference laboratories

\begin{tabular}{ll}
\hline Country & Sentinel site \\
\hline Brazil & I. Laboratório de Hanseniase FIOCRUZ, Rio de Janeiro, RJ \\
& 2. Centro de Referência Nacional em Dermatologia Sanitária Dona \\
& Libânia, Fortaleza, CE \\
3. Fundação Alfredo da Matta, Manaus, AM & 4. Instituto Lauro de Souza Lima, Bauru, SP \\
& 5. Centro de Referência Estadual em Dermatologia Sanitária e \\
& Hanseníase, Uberlândia, MG \\
& 6. Unidades de Referência Especializada - URES, Dr Marcello Cândia, \\
& Marituba, PA \\
Benin & National Leprosy Control Programme is responsible for collecting samples \\
& Raoul Follereau Foundation supports sample collection
\end{tabular}

People's Institute of Dermatology and National Center for Leprosy Control, Republic of Nanjing

China

Colombia Instituto Colombiano de Medicina Tropical Universidad, CES, Medellin

Ethiopia I. Dermatology Department, All Africa Leprosy, Tuberculosis and Rehabilitation Training (ALERT) Hospital, Addis Ababa

2. Armauer Hansen Research Institute (AHRI), Addis Ababa

Guinea National Leprosy Control Programme is responsible for collecting samples

Raoul Follereau Foundation supports sample collection

India I. The Leprosy Mission (TLM) Community Hospital, Shahdara, New Delhi

2. National JALMA Institute for Leprosy and Other Mycobacterial Diseases, Agra

3. Blue Peter Research Center, Hyderabad

Indonesia I. Soetomo Hospital, Airlangga University, Surabaya

2. Leprosy Unit, Cipto Mangunkusumo Hospital, Faculty of Medicine, University of Indonesia, Jakarta

Ivory Coast National Leprosy Control Programme is responsible for collecting samples Raoul Follereau Foundation supports sample collection

Madagascar I. Pavillon du Père Isidore Depré (PPID) Tuléar

2. Salfa Hospital Bekoaka

3. Ekar Marana-

4. Ekar Tsarahonenana-

5. Ekar Marovahy-

6. Ekar St François Ambanja

Raoul Follereau Foundation supports sample collection

Mali National Leprosy Control Programme is responsible for collecting samples Raoul Follereau Foundation supports sample collection

Mozambique Instituto da Saúde in Maputo is responsible for sample collection

Myanmar I. Central Special Skin Clinic, Yangon General Hospital, Yangon

2. Central Special Skin Clinic, Mandalay General Hospital, Mandalay

Niger National Leprosy Control Programme is responsible for collecting samples Raoul Follereau Foundation supports sample collection

Nepal Anandaban Hospital, Kathmandu
Reference laboratory

I. Laboratório de Hanseniase FIOCRUZ, Rio de Janeiro, RJ

2. Fundação Alfredo da Matta, Manaus, AM

3. Instituto Lauro de Souza Lima, Bauru, SP

I. National Reference Center on Mycobacteria and Resistance to Anti-tuberculosis Drugs, Saint Louis Hospital, Paris, France

2. Global Health Institute, École Polytechnique Fédérale de Lausanne, Switzerland

Institute of Dermatology and National Center for Leprosy

Control, Nanjing, People's Republic of China

PCR products are analyzed by a commercial company Instituto Colombiano de Medicina Tropical, Universidad, CES, Medellin, Colombia

PCR products are analyzed by a commercial company National Reference Center on Mycobacteria and Resistance to Anti-tuberculosis Drugs, Saint Louis Hospital, Paris, France

I. National Reference Center on Mycobacteria and Resistance to Anti-tuberculosis Drugs, Saint Louis Hospital, Paris, France

2. Global Health Institute, École Polytechnique Fédérale de Lausanne, Switzerland

I. Stanley Brown Laboratory

2. JALMA, Agra, India

3. Blue Peter Research Center, Hyderabad, India

I. Tropical Disease Center, Airlangga University, Surabaya

2. Microbiology Department, University of Indonesia, Jakarta

National Reference Center on Mycobacteria and Resistance to Anti-tuberculosis Drugs, Saint Louis Hospital, Paris, France National Reference Center on Mycobacteria and Resistance to Anti-tuberculosis Drugs, Saint Louis Hospital, Paris, France

I. National Reference Center on Mycobacteria and Resistance to Anti-tuberculosis Drugs, Saint Louis Hospital, Paris, France

2. Global Health Institute, École Polytechnique Fédérale de Lausanne, Switzerland

Leprosy Research Center, Tokyo, Japan

Leprosy Research Center, Tokyo, Japan

I. National Reference Center on Mycobacteria and Resistance to Anti-tuberculosis Drugs, Saint Louis Hospital, Paris, France

2. Global Health Institute, École Polytechnique Fédérale de Lausanne, Switzerland

Anandaban Hospital, Kathmandu PCR products are analyzed by commercial company 
Table 3 (Continued)

\begin{tabular}{lll}
\hline Country & Sentinel site & Reference laboratory \\
\hline Pakistan & Rawalpindi Leprosy Hospital, Rawalpindi & National Hansen's Disease Programs, Laboratory Research \\
Philippines & Skin Clinic, Leonard Wood Memorial, Cebu & Branch, Baton Rouge, USA \\
& & National Hansen's Disease Programs, Laboratory Research \\
Vietnam & I. National Institute of Dermatology and Venereology, Hanoi & Branch, Baton Rouge, USA \\
& 2. Quy Hoa National Leprosy Dermatology Hospital, Quy Nhon & I. Yonsei University College of Medicine, Seoul, South Korea \\
Yemen & Skin and Venereal Disease Hospital, Taiz & 2. Leprosy Research Center, Tokyo, Japan \\
& & National Reference Center on Mycobacteria and Resistance \\
\end{tabular}

in the diet, ${ }^{52}$ although not all isolates are inhibited at this concentration. ${ }^{53}$ Those isolates that grow in the footpad of a mouse treated with $0.0001 \%$ dapsone in the diet are classified as low-degree resistance. None of ten isolates with a low degree of dapsone resistance carried mutations in the folP1 gene. ${ }^{22,23}$ However, such cases have no clinical significance, since administration of $0.0001 \mathrm{~g}$ DDS/100 g mouse diet would be similar to humans receiving $1 \mathrm{mg}$ DDS daily, much less than the typical dosage of $100 \mathrm{mg}$ daily. ${ }^{3,54}$ A dapsone concentration of $0.0001 \%$ appears to be a critical point: strains grown in the footpad of mice treated at this concentration can produce equivocal resistance data.

Although biopsy samples should be kept in child patients, the bacillary suspension for footpad inoculation must be prepared within 1 week. Clinical samples such as bacilli obtained by slit skin smear or biopsy can be kept in $70 \%$ ethanol at room temperature until DNA extraction for PCR and subsequent direct sequencing of DRDRs. Isolates with known missense mutations are regarded as drug resistant.

In the mouse foot pad assay, some isolates do not multiply in control mouse footpads, and their drug susceptibility cannot be determined using this method. In contrast, DNA sequencing of PCR products is independent of M. leprae viability. Among 83 isolates, only 46 could be tested for drug susceptibility by the mouse footpad method while 79 could be sequenced and susceptibility determined through their genetic profile. ${ }^{22}$ These results reveal the usefulness of molecular applications for susceptibility testing.

\section{Sentinel surveillance of drug resistance by the WHO Global Leprosy Control Programme}

Current leprosy control mainly depends on early disease detection and an MDT chemotherapy regimen consisting of dapsone, rifampicin, ofloxacin, clofazimine, and minocycline (Table 1). Resistance to dapsone, rifampicin, and ofloxacin can be detected by molecular techniques as mentioned above. Although detecting resistance to clofazimine and minocycline by the sequence analysis of specific genes is not applicable, the frequency of drug resistance to clofazimine is negligible and resistance to minocycline has not been observed.

Understanding the magnitude of drug resistance is essential in maintaining the effectiveness of the current MDT strategy, and in preventing the spread of drug-resistant strains. Although drug-resistant cases or prevalence of resistance in some areas have been reported occasionally, global comprehensive data were not available. Resistance to rifampicin, a key component of MDT, was of great concern for the GLP. Therefore, WHO established a sentinel network in 2008 using direct sequencing for global surveillance of drug resistance to keep a close vigil on drug resistance scenarios at many vulnerable settings. ${ }^{55}$ Prior to launching surveillance, an informal consultation was held in Agra, India in 2006. The meeting stated the overall aims to establish a surveillance network using a standardized approach to detect secondary drug resistance, particularly rifampicin resistance, among leprosy patients and to monitor resistance trends. The first workshop was held in Hanoi, Vietnam in 2008. Sentinel sites were set up in Brazil, Ethiopia, India, Mali, Myanmar, and Vietnam. The structure of the surveillance is shown in Figure 4. Samples collected at each site are sent for mutation analysis at each reference laboratory. Sequencing results are returned to the sentinel site and the department with oversight over leprosy control in the Ministry of Health. Each country reports the results to GLP, and GLP compiles data globally and reports it in a weekly epidemiology report. The data are also sent to the Global Health Institute, École Polytechnique Fédérale de Lausanne. The Global Health Institute retains the mutation data to compute the frequency of each mutation worldwide in each area. Although the first sentinel sites were set in these six countries, many other sentinel sites are currently participating in the project (Table 3). A workshop is held annually to discuss method revisions and update the data. The guidelines originally recommended analyzing only relapsed cases. However, during the 5th workshop held in Cotonou, Benin, in November 2012, it was agreed that samples from new cases would be included in the analysis protocol. WHO guidelines provide details for template DNA preparation, PCR conditions, and sequencing methods, but 
in the workshop held in Tokyo, 2010, reference laboratories agreed to employ the preferred procedures of each laboratory for PCR and direct sequencing. Quality control studies were performed four times to evaluate and qualify the capabilities of each reference laboratory.

The data obtained in 2009 and 2010 indicate that the level of drug resistance has not reached a level that would threaten MDT regimens for leprosy control. ${ }^{56,57}$ Samples of relapsed cases from Brazil, People's Republic of China, Colombia, Myanmar, and Vietnam were analyzed in 2009 ${ }^{56}$ Although 213 samples were analyzed, some cases were PCR negative and could not be sequenced. Of 92 folP 1 PCR positives, 12 (13\%) contained a mutation and were resistant to dapsone; of 108 rpoB PCR positives, 9 (8\%) were rifampicin resistant; and of 108 gyrA PCR positives, 2 (2\%) were quinolone resistant. In 2010, a total of 88 samples from Brazil, People's Republic of China, Colombia, India, Pakistan, Myanmar, and Vietnam were examined. ${ }^{57}$ Of 63 PCR positives for the folP1 gene, 9 (14\%) were resistant to dapsone; of $71 \mathrm{PCR}$ positives for the $r p o B$ gene, 7 (1\%) were resistant to rifampicin; and none of the 63 gyrA gene PCR positive samples harbored a mutation. Further data are not reported in the weekly epidemiology record, but informal data reported at the 2012 workshop are available. ${ }^{58}$ During 2011, 445 samples were analyzed for relapsed cases in Brazil, the Philippines, Colombia, India, Vietnam, and Myanmar. The ratios of resistant isolates were $4.5 \%$ for dapsone, $2.0 \%$ for rifampicin, and $1.8 \%$ for quinolone.

Surveillance found certain cases of dapsone resistance in M. leprae. The data obtained to date indicate that the level of drug resistance in $M$. leprae is low enough and is not a serious concern for global leprosy control. Multidrug resistance is a major concern, but it has not been detected by the current surveillance structure. Improvement of the system is required. Results have not been published in the weekly epidemiological report since 2011. Continuous information would be informative in determining and following resistance trends. Looking forward, a surveillance system that can provide worldwide comprehensive and longitudinal data for drug resistance is needed to prevent dissemination of resistant strains and pursue better strategies for leprosy control.

\section{Disclosure}

The author reports no conflicts of interest in this work.

\section{References}

1. Robins G, Tripathy VM, Misra VN, et al. Ancient evidence for leprosy in India (2000 BC). PLoS One. 2009;4:e5669.

2. World Health Organization. Global leprosy update, 2013; reducing disease burden. Wkly Epidemiol Rec. 2014;89:389-400.
3. World Health Organization. WHO Expert Committee on Leprosy: 8th Report. Geneva: World Health Organization. Available from: http://www. searo.who.int/entity/global_leprosy_programme/publications/8th_ expert_comm_2012.pdf. Accessed August 3, 2015.

4. Pettit JHS, Rees RJW. Sulphone resistance in leprosy. An experimental and clinical study. Lancet, 1964;26:673-674.

5. Grosset JH, Guelpa-Lauras C-C, Bobin P, et al. Study of 39 documented relapses of multibacillary leprosy after treatment with rifampin. Int $J$ Lepr Other Mycobact Dis. 1989;557:607-614.

6. Jacobson RR, Hastings RC. Rifampin-resistant leprosy. Lancet. 1976;2: 1304-1305.

7. Guelpa-Lauras CC, Grosset JH, Constant-Desportes M, Bruker G. Nine cases of rifampicin-resistant leprosy. Int J Lepr Other Mycobact Dis. 1984;52:101-102.

8. Maeda S, Matsuoka M, Nakata N, et al. Multidrug resistant Mycobacterium leprae from Patients with leprosy. Antimicrob Agents Chemother. 2001;45:3635-3639.

9. Matsuoka M. Drug resistance in leprosy. Jpn J Infect Dis. 2010;63: $1-7$.

10. Jacobson RR. Treatment of leprosy. In: Hastings RH, editor, Leprosy. Edinburgh: Churchill Livingston; 1994;317-349.

11. Saunderson P. Chemotherapy. In: Makino M, Matsuoka M. Goto M, Hatano K, editors. Leprosy. Kanagawa: Tokai University Press; 2011:145-153.

12. Faget GH, Pogge RC, Johansen FA, Dinan JF, Prejean BM, Eccles CC. The promin treatment of leprosy: a progress report. Pub Health Rep. 1943;58:1729-1741. (Reprint Int J Lepr Other Mycobact Dis. 1966;34: 298-310).

13. Lowe J. Treatment of leprosy with diamino-diphenyl sulphone by mouth. Lancet. 1950;1(6596):145-150.

14. Cochrane RG, Ramanujam K, Paul H, Ressel D. Two-and a half year's experimental work on the sulphone group of drugs. Lepr Rev. 1949;20: 4-64.

15. Agrawal S, Agarwalla A. Dapsone hypersensitivity syndrome: a clinicoepidemiological review. J Dermatol. 2005;32:883-889.

16. Wolcott RR, Ross SH. Exacerbation of leprosy during present day treatment. Int J Lepr Other Mycobact Dis. 1953;21:437-440.

17. Shepard CC. The experimental disease that follows the injection of human leprosy bacilli into foot-pad of mice. J Exp Med. 1960;112: 445-454.

18. Pearson JMH, Rees RJW, Waters MFR. Sulphone resistance in leprosy. A review of one hundred proven clinical cases. Lancet. 1975;12: 69-72.

19. dela Cruz E, Cellona RV, Balagon MVF, et al. Primary dapsone resistance in Cebu, the Philippines; cause for concern. Int J Lepr Other Mycobact Dis. 1996;64:253-256.

20. Kai M, Matsuoka M, Nakata N, et al. Diaminodiphenylsulfone resistance of Mycobacterium leprae due to mutations in the dihydropteroate synthase gene. FEMS Microbiol Lett. 1999;177:231-235.

21. Williams DL, Spring L, Harris E, Roche P, Gillis TP. Dihydropteroate synthase of Mycobacterium leprae and dapsone resistance. Antimicrob Agents Chemother. 2000;44:429-432.

22. Cambau E, Carthagena L, Cahuffour A, Ji B, Jarlier V. Dihydropteroate synthase mutations in the folPl gene predict dapsone resistance in relapsed cases of leprosy. Clin Infect Dis. 2006;42:238-241.

23. Matsuoka M, Budiawan T, Khin SA, et al. The frequency of drug resistance mutations in Mycobacterium leprae isolates in untreated and relapsed leprosy patients from Myanmar, Indonesia and the Philippines. Lepr Rev. 2007;78:343-352.

24. Matsuoka M. The history of isolates maintained at the Leprosy Research Center. Jpn J Lepr. 2010;79:247-256.

25. Williams DL, Pittman TL, Gillis TP, Matsuoka M, Kashiwabara Y. Simultaneous detection of Mycobacterium leprae and its susceptibility to dapsone using heteroduplex analysis. J Clin Microbiol. 2001;39: 2083-2088.

26. Williams DL, Gillis TP. Drug resistant leprosy: monitoring and current status. Lepr Rev. 2012;83:269-281. 
27. Musser A. Antimicrobial agent resistance in mycobacteria: molecular genetic insights. Clin Miclobol Rev. 1995;8:496-514.

28. Honore N, Cole ST. Molecular basis of rifampin resistance in Mycobacterium leprae. Antimicrob Agents Chemother. 1993;37:414-418.

29. Williams DL, Waguespack C, Eisenach K, et al. Characterization of rifampin resistance in pathogenic mycobacteria. Antimicrob Agents Chemother. 1994;38:2380-2386.

30. Cambau E, Bonnafous P, Perani E, Sougakoff S, Ji B, Jarlier V. Molecular detection of rifampin and ofloxacin resistance for patients who experience relapse of multibacillary leprosy. Clin Infect Dis. 2002;34:39-45.

31. Cambau E, Perani E, Guillemin I, Jamet P, Ji B. Multidrug-resistance to dapsone, rifampicin, and ofloxacin in Mycobacterium leprae. Lancet. 1997;349:103-104.

32. Matsuoka M, Kashiwabara Y, Namisato Y. A Mycobacterium leprae isolate resistant to dapsone, rifampin, ofloxacin, and sparfloxacin. Int J Lepr Other Mycobact Dis. 2000;68:452-455.

33. Zhang L, Namizato M, Matsuoka M. A mutation at codon 516 in the $r p o B$ gene of Mycobacterium leprae confers resistance to rifampin. Int $J$ Lep Other Mycobact Dis. 2004;72:468-472.

34. Morrison NE, Marley G. Clofazimine binding studies with deoxyribonucleic acid. Int J Lepr Other Mycobact Dis. 1976;44:475-481.

35. Kroger A, Pannikar V, Htoon MT, et al. International open trial of uniform multi-drug therapy regimen for 6 months for all types of leprosy patients: rationale, design and preliminary results. Trop Med Int Health 2008;13:594-602.

36. Shetty VP, Uplekar MV, Antia NH. Primary resistance to single and multiple drugs in leprosy - a mouse footpad study. Lepr Rev. 1996;67: 280-286.

37. Diepen TWV. Clofazimine-resistant leprosy, a case report. Int J Lepr Other Mycobact Dis. 1982;50:139-142.

38. Levy L. Clofazimine-resistant M. leprae. Int J Lepr Other Mycobact Dis. 1986;54:137-140

39. Takiff HE, Salazar L, Guerrero C, et al. Cloning and sequencing of Mycobacterium tuberculosis gyrA and gyrB genes and detection of quinolone resistance mutation. Antimicrob Agents Chemother. 1994;38: 773-780.

40. Cambau E, Saugacoff W, Besson M, et al. Selection of a gyrA mutant of Mycobacterium tuberculosis resistant to fluoroquinolones during treatment with ofloxacin. J Infect Dis. 1994;170:479-483.

41. Matsuoka M, Kashiwabara Y, Zhang LF, Goto M, Kitajima S. A second case of multidrug-resistant Mycobacterium leprae isolated from a Japanese patient with relapsed lepromatous leprosy. Int J Lepr Other Mycobact Dis. 2003;71:240-243.

42. You EY, Kang TJ, Kim SK, Lee SB, Chae GT. Mutations in genes related to drug resistance in Mycobacterium leprae isolates from leprosy patients in Korea. $J$ Infect. 2005;50:6-11.

43. Matsuoka M, Suzuki Y, Garcia IE, et al. Possible mode of emergence for drug resistant leprosy is revealed by an analysis of samples from Mexico. Jpn J Infect Dis. 2010;63:412-416.
44. Rocha AS, Cunha MG, Diniz L, et al. Drug and multiple-drug resistance among Mycobacterium leprae isolates from Brazilian relapsed leprosy patients. J Clin Microbiol. 2012;50:1912-1917.

45. Cambau E, Jarlier V. Resistance to quinolones in Mycobacteria. Res Microbiol. 1996;147:52-59.

46. Matrat S, Cambau E, Jarlier V, Aubry A. Are all the DNA gyrase mutations found in Mycobacterium leprae clinical strains involved in resistance to fluoroquinolones? Antimicrob Agents Chemother. 2008;52: $745-747$.

47. Yokoyama K, Kim H, Mukai T, et al. Amino acid substitution at position 95 in GyrA can add fluoroquinolone resistance to Mycobacterium leprae. Antimicrob Agents Chemother. 2012;56:697-702.

48. Taylor DE, Chau A. Tetracycline resistance mediated by ribosomal protection: mini review. Antimicrob Agents Chemother. 1996;40:1-5.

49. Chan GP, Garcia-Ignacio BY, Chavez VE, et al. Clinical trial of sparfloxiacin for lepromatous leprosy. Antimicrob Agents Chemother. 1994;38:61-65.

50. World Health Organization. Chemotherapy of Leprosy for Control Programmes. Report of a WHO Study Group. Technical Report Series No 675. Geneva: World Health Organization; 1982. Available from: http:// apps.who.int/iris/bitstream/10665/38984/1/WHO_TRS_675.pdf?ua=1. Accessed August 3, 2015.

51. Ridley DS, Jopling WH. Classification of leprosy according to immunity - a five group system. Int J Lepr Other Mycobact Dis. 1966;34: 255-273.

52. Shepard CC, Rees RJ, Levy L, Pattin ASR, Ji B, dela Cruz EC. Susceptibility of strains of Mycobacterium leprae isolated prior to 1977 from patients with previously untreated lepromatous leprosy. Int J Lepr Other Mycobact Dis. 1986;54:11-15.

53. Rees RJ. Drug resistance of Mycobacterium leprae particularly to DDS Int J Lep Other Mycobact Dis. 1967;35:625-636.

54. Ji B. Drug susceptibility testing of Mycobacterium leprae. Int J Lepr Other Mycobact Dis. 1987;55:830-835.

55. World Health Organization. Guidelines for Global Surveillance of drug Resistance in Leprosy. EW-GLP 2009. Geneva: World Health Organization. Available from: http://www.searo.who.int/entity/ global_leprosy_programme/publications/guide_surv_drug_res_2009. pdf. Accessed August 5, 2015.

56. World Health Organization. Surveillance of drug resistance in leprosy: 2009. Wkl Epidemiol Rec. 2010;85:281-284.

57. World Health Organization. Surveillance of drug resistance in leprosy: 2010. Wkl Epidemiol Rec. 2011;86:237-240.

58. World Health Organization. Meeting on Sentinel Surveillance for Drug Resistance in Leprosy. Geneva: World Health Organization. Available from: http://www.searo.who.int/entity/global_leprosy_programme/ publications/sentinel_surv_meeting_2010.pdf?ua=1. Accessed August 5, 2015.
Research and Reports in Tropical Medicine

\section{Publish your work in this journal}

Research and Reports in Tropical Medicine is an international, peerreviewed, open access journal publishing original research, case reports, editorials, reviews and commentaries on all areas of tropical medicine, including: Diseases and medicine in tropical regions; Entomology; Epidemiology; Health economics issues; Infectious disease; Laboratory

\section{Dovepress}

science and new technology in tropical medicine; Parasitology; Public health medicine/health care policy in tropical regions; and Microbiology. The manuscript management system is completely online and includes a very quick and fair peer-review system. Visit http://www.dovepress. com/testimonials.php to read real quotes from published authors. 